\title{
Semiotics: Important Way for Improving College Students' Abilities of Images Reading and Critical Thinking
}

\author{
Baolei Yang ${ }^{1}$ Guo Zhao ${ }^{2, *}$
}

\author{
${ }^{1}$ Jinan University \\ ${ }^{2}$ Jinan University \\ *Corresponding author. Email: 862091828@qq.com
}

\begin{abstract}
In the context of visual culture, it is an important way for college students to master semiotic knowledge to improve their images-reading abilities and cultivate critical thinking. Image interpretation can draw lessons from Saussure's three pairs of symbolic concepts -- signifier and signified, combination and aggregation, diachronic and synchronic, recognize the narrative structure of image texts, deeply recognize the logic of image production, and rationally carry out visual text criticism. Pierce's sign triad method--Icon, index, and symbol are used, to excavate the energy value and emotional tension of images, critically recognize the deep meanings of image texts, and identify the connotation of images based on cultural contexts.
\end{abstract}

Keywords: Symbol, Saussure, Pearce.

\section{INTRODUCTION}

Today's college teaching environment has been strongly influenced by "visual shift". In this regard, as early as in the 1960s, Heidegger predicted the arrival of the "world image era", which is that the world was conceived and grasped as an image. [1] "Our age is a visual age," Gombrich said, "We are invaded by pictures from morning till night."[2] Aiming at the current social situation in which visuality has become the main cause of culture, William Michel called the visual cultural logic "Pictorial Turn." Under the visual cultural background of image construction, domestic scholar Zhou Xian also pointed out that "visual factor has become the core element of contemporary culture and an important means of creation, representation and transmission of meaning".[3]

In the context of visual culture, to adapt to students' interest in reading visual texts (pictures, videos, etc.) and to grasp students' concerns and concerns are issues that need to be paid special attentions in the reform of college education and teaching. Therefore, integrating visual elements into teaching contents, paying attention to visual display in teaching form, and cultivating visual thinking in teaching are important contents for cultivating college students under the current visual culture contexts. In other words, improving college students' abilities to read pictures and cultivating their critical thinking in image interpretation is one of the important goals of today's college education and teaching. As the American Board of Education report notes, "the most important purpose of undergraduate education is to develop students' critical thinking skills." The development of critical thinking is of great importance to both individual success and national needs. Based on this, this research focuses on the core question: how college students can improve their abilities to read pictures in the face of visual cultural contexts? How to develop their critical thinking skills?

In order to find a specific ways to improve college students' abilities to read pictures and cultivate critical thinking, this study mainly adopts the methods of case analysis, text analysis, questionnaire survey and interview. Case analysis mainly examines the typical cases that are conducive to the development of college students' abilities to read pictures and critical thinking, such as image events closely related to social issues, and analyzes them from the perspective of semiotics. Text analysis is mainly used for semiotic analysis, discourse analysis and narrative analysis of multi-modal texts such as images, texts and videos in cases. Questionnaire method is mainly aimed at students in classroom teaching, and relevant questionnaires are filled in classroom teaching content, teaching arrangement, teaching design and other aspects. In order to further understand the effect of this study in classroom teaching, this study also adopts the interview method to understand the students' personal feelings about whether and how to affect their abilities to read pictures and critical thinking after learning the theory of semiotics, so as to enrich the effect research. Through analysis, combined with semiotics, this study finds and summarizes effective ways to improve college students' 
abilities to read pictures and cultivate their critical thinking in the context of visual culture.

\section{DRAW LESSONS FROM SAUSSURE'S THREE PAIRS OF SIGNS CONCEPTS}

Saussure is a representative scholar in the field of semiotics. His discussion of symbols from the aspects of signification and signification, combination and aggregation, diachronic and synchronous is conducive to guiding college students to dig deeper into the connotation of images.

\subsection{Use Symbols Signifier and Signified}

Saussure once pointed out that symbols are composed of signifiers and signifiers. Signifier is form, signified refers to the involved object and its meanings. Identifying signifier and signified can help us to recognize the narrative structure of image texts. For the 2019 Spring Festival, the Dapeng team created "what Is Peppa Pig", a visual short film popular among college students. In the film, the grandfather asks his grandson, who is going to return to his hometown for Chinese New Year, what gift he would like? Grandson answers: Paige. At that time, grandpa only heard the pronunciation of "Paige" -- the form, the signifier of Paige, but did not know the meaning behind it. Thus, the narrative structure of the entire film revolves around grandpa's search for Page's "signified" process. We saw the Paige dishwashing liquid, Peppa Zhang--grandpa's good friend, a game called Paige, a real pig... in the short film. In fact, they are all the signifiers of the signifier "Page". In this dimension, grandpa's love for his grandson is reflected in the whole process of trying to find Page's "reference", which forms a tender narrative structure of the whole film.

\subsection{Adopt Symbol Combination and Aggregation Perspective}

Saussure, combined with Jacobson's research, pointed out the relationship between symbol combination and aggregation. Wherein, the combination relation refers to the adjacency between symbols, which is a kind of adjacency and connection relation; the aggregation relation is a kind of comparison, selection and association relation. The two are like $\mathrm{X}$-axis/The horizontal axis and Y-axis/ The vertical axis in coordinate axis. All symbols on the combinatorial relation/horizontal axis can be presented to the audience at the same time, while symbols on the aggregation relation/vertical axis usually cannot be presented to the audience at the same time, because it is the result of comparison and selection among a class of symbols by the producer. Therefore, when audience see symbols, it will trigger the vertical association associated with one symbol, and deeply recognize the image production logic.

When students have the combination and aggregation thinking, they will have a deeper understanding when re-examining the case of Ziqi Li, which is popular all over the world. For example, when college students examine a picture of Ziqi Li's performance, on the one hand, they can analyze the combination of multiple symbols in the picture -- Ziqi $\mathrm{Li}$ herself (hairstyle, clothes, actions), props and the environment, and analyze the image connotation constructed by the combination of symbols. On the other hand, it can also be analyzed from the perspective of symbol aggregation -- looking at Ziqi Li picking grapefruit, which can make audience think of her picking pears, oranges, apples... Through the pomelo forests, it is associated with bamboo forests, ancient streets, courtyards, kitchens and other environments where performance activities are carried out. Through the analysis from the perspective of symbol combination and aggregation, the students find that as a text producer and idea creator, Ziqi Li is able to continuously combine symbols, produce images and texts that are popular with the audience, and strengthen her personal communication value, thus facilitating the realization of commercial purposes in the context of consumer culture.

\subsection{Reference Symbol Diachronic and Synchronic Perspective}

Diachronic analysis is that, we need to understand the meaning of symbols in the past, present and future in the "change" of symbols, and grasp the change of symbols' connotations. For example, when students were asked, "Do you think beauty is fatter or thinner?" The majority of students answered, "of course, thinner is more beautiful!" However, to examine this issue, we need put "beauty" into different contexts to examine. In Han Dynasty, people regarded "thin" as the aesthetic standard, so Zhao Feiyan became the goddess of Han Dynasty. In Tang Dynasty, "fullness" was the standard of beauty, so Yang yuhuan became a goddess. Our preference for thinness today is actually a contemporary aesthetic standard constructed by multiple contexts such as visual culture and consumer culture. Therefore, it is necessary to have a diachronic perspective and thinking to examine beauty and any other symbols, and to carry out visual criticism rationally.

The cultivation of critical thinking not only depends on diachronic perspective, but also needs to have a synchronic perspective. When a combination of symbols is seen as a text, or as a system, they are synchronic [4]. In other words, the audience needs to put symbolic text together and examine it at the same time. Yu Aihua, party secretary of Anqing, made a speech at the launching ceremony of the 100-day countdown to the 
13th Anhui Provincial Games in July 2014. A picture of the scene speech of the secretary yu immediately made him famous. The first message students read when they examined the pictures was that the secretary was very frugal -- he wrote his speeches on the old calendar. At the same time, there is another symbol in the picture -mineral water, whose value is 35 yuan. Media reports represented the headline -- "Anqing secretary meeting speech use a calendar meeting, and the meeting useed high-grade water 35 yuan a bottle". Thus, in symbolic synchronic analysis, it is usually ok to analyze a single symbol, but it is often easy to find problems when we combine symbols (especially those with opposite connotations) and examine them.

\section{USE PEARCE'S METHOD OF SIGN THIRDS}

Pierce's understanding of symbols is mainly reflected in the classification of symbol types, including three types of iconicity, indicator and specification. Therefore, to find a way to improve reading abilities and cultivate critical thinking can be analyzed from the three dimensions of icon, index and symbol, to deep visual image thinking abilities.

\subsection{Use Icon to Mine Emotional Tension of Images}

Icon refers to symbols that have similar relationships with the objects they refer to, such as maps, murals, photographs, sculptures, and simulated sounds. News pictures in communication contexts are basically iconographies. Because icon is similar to real subjects in reality, it is more realistic and easier to arouse audience's emotion. For example, one of the students' most impressive images--"The Syrian Boy" is an Iconography. Alan, a 3-year-old boy, was killed in a storm while trying to escape with his parents in a small boat. The next day, a reporter took a picture of little Alan on the beach. Before this, Syrian refugee crisis has lasted for a long time, but it has not attracted enough attention from countries around the world. It was only after this iconic news image was published, which triggered a strong response from countries around the world - they have changed their rules for accepting Syrian refugees. Thus it can be seen that icon has strong emotional appeal, which makes it can often transmit great emotional energy, then exert its persuasive function to audience.

\subsection{Use Index to Critically Perceive Deep Meanings of Image Texts}

In icon, signifier of a symbol bears formal resemblance to the signified object. Whereas In index, signifier and signified are an indicator relationship. In other words, symbols and their objects hint at each other because of some relationships, such as causality/adjacency/partial and whole relationships, so as to make receivers can think of objects through seeing the signifier of a symbol. For example, the relationship between lightning, thunder and rain, which is not due to similarity, but based on correlation. So we can say that lightning and thunder are indexs.

When a person's desire shifts from objects to substitution symbols, which indicates a crisis. For example, in TV series "In the Name of The People", when Hou Liangping, director of the Supreme People's Procuratorate's Anti-corruption bureau, search in the home of a project director of a national ministry, and finds a large amount of RMB. The RMB is an indicator, which represents value, but itself has no value. An official's excessive lust for symbols is bound to get himself into trouble. In history, similar cases also exist. During The Three Kingdoms Period, When Sun Jian arrived at the old capital abandoned by Emperor of Eastern Han Dynasty, he was extremely happy to find "Imperial Seal". His son Sun Ce thought that was not a good thing -- Sun Jian's power at that time was not enough to support the signified behind that symbol "Seal". Excessive greed reflected imbalance between signifier and signified. It is because of that "Seal", on Sun Jian's way back to Jiangdong, he was killed by Liu Biao. Therefore, reviewing index can help us critically perceive deep connotation of visual texts.

\subsection{Use symbol to Identify Image Connotation Based on Cultural Context}

Symbol is the relationship between symbolic form and meaning by social conventions. In cross-cultural communication, when reading image texts, students need to understand symbol and make comprehensive analysis based on different cultural contexts. For example, in the context of "One Belt, One Road", the Red Cross Society of China changed its logo to the green cross society when assisted Africa, which involved knowledge of symbol. In Chinese cultural context, red coulor symbolizes auspiciousness and happiness. Influenced by the October Revolution and the Chinese revolution since modern times, red coulor also symbolizes revolution and dedication connotations. In contrast, red coulor in some Western countries is a symbol of blood and ominous connotations. Such a prescriptive and conventionalized interpretation of symbol connotation is related to the context of Chinese and Western culture. Therefore, students need to identify conventions and different cultural contexts to comprehend visual texts, and grasp the connotation of visual symbols in cross-cultural communication. 


\section{CONCLUSION: SEMIOTICS AS IMPORTANT WAYS FOR IMPROVING ABILITIES}

This research is carried out throughout the whole process of classroom education and teaching. Through several research methods, we find that today's college students are generally interested in visual forms for classroom teaching. Integrating relevant theoretical perspective of semiotics into classroom teaching process can generally improve students' abilities to read pictures and critical thinking.

Our survey results show that students are generally interested in visual contents. $96.92 \%$ of students expect their teacher can play one or two short videos in each class. $93.65 \%$ of students hope that short videos playing in class is for less than 10 minutes, among which $49.21 \%$ think short videos playing 5-10 minutes is appropriate. $73.75 \%$ of students think it is very important or relatively important to improve their reading abilities. More than $70 \%$ of students expect teachers can adopt visual teaching methods, such as try to use pictures and video links in each PPT page. In 80 minutes class, $72.31 \%$ of the students think it is more appropriate for their teacher to give lectures for 51-60 minutes, and leave other time for students, which is used for interaction, sharing and so on.

After learning relevant knowledge of semiotics, students believe that their abilities to read pictures and critical thinking have been greatly improved. According to the results of the questionnaire survey, $95.38 \%$ of students believed that semiotic perspective effectively improved their abilities to read pictures, which brought great help to the improvement of their cognitive and thinking abilities. In addition, through interviews, our study found that more students believed that how semiotics knowledge was helpful to their improvement of graph reading abilities and the cultivation of critical thinking. Some students' answers are as follows:

"The knowledge of semiotics enables me to have more comprehensive and profound understanding of the understanding, analysis and interpretation of image contents" (Student No.18).

"I feel that semiotics has greatly improved my logical thinking, writing and text analysis abilities" (Student No.64).

"I am able to interpret symbols in daily life, which enriched my perspective on problems and improved my depth of thinking" (Student No.30).

To sum up, in the context of visual culture, it is necessary to learn from the relevant theoretical perspectives of semiotics to improve college students' abilities to read pictures and cultivate their critical thinking. Saussure's discussions on signifier and signified, combination and aggregation of symbols, diachronic and synchronal, and Pearce's icon, index and symbol are all conducive to improve college students abilities to read pictures and cultivation of critical thinking. College students need to think and explore independently on basis of professional knowledge, which is to think about their own positions, arguments and reasoning, so as to develop their abilities to read pictures and critical thinking. Because "critical thinking is the premise and foundation of innovative thinking, which is the guarantee of high-quality innovation, the most core content of innovative thinking, and the practical operation mode of innovative thinking. It is through the training of critical thinking that European and American universities improve students' abilities of innovative thinking." In China, to realize the creative thinking of college students, it is necessary to further improve their abilities of reading pictures and cultivate critical thinking in the context of visual culture.

\section{PROJECT FUNDS}

This paper is a phased achievement for Youth Project of Humanities and Social Sciences of Ministry of Education "Research on The Visual Rhetoric Production and Visual Communication Strategies of National Image" (19YJC860041).

\section{REFERENCES}

[1] M. Heidegger, Forest Road, translated by Sun Zhouxing, Shanghai Translation Publishing Press, 2004.p.91

[2] M. Gombrich. Images and Eyes: A Restudy of the Psychology of Pictorial Representation, Guangxi Fine Arts Publishing Press, 2013.p.128

[3] M. Zhou Xian, The Turn of Visual Culture, Peking University Press, 2008.p.6

[4] M. Zhao Yiheng, Semiotics, Nanjing University Press, 2012.p.75 